\title{
Challenges and Opportunities of Milk Production in Urban Dairy Farms in Ethiopia: A Review
}

\author{
Nibo Beneberu ${ }^{1,2^{*}} \quad$ Zewdu Wondifraw ${ }^{3}$ \\ 1.Bahir Dar University, Colleges of Agriculture and Environmental Science, Bahir Dar, Ethiopia \\ 2 Ethiopia.n Institute of Agricultural Research, Holeta Agricultural Research Center, P.O.Box: 2003 Addis \\ Ababa or 31, Holeta, Ethiopia \\ 3.Debre Markos University, Animal Science Department, Debre Markos, Ethiopia
}

\begin{abstract}
Ethiopia is one of the developing countries in Africa with a huge livestock population. The huge and diverse cattle populations, diverse and favorable agro-ecology for dairying, long-standing culture of dairy products consumption, increasing demand for dairy products in urban areas, potential of dairying in the country and favorable policy are indicators of dairy production. However, the production and productivity of dairy animals in general is insufficient and this results in short supply of dairy products. The main objective of this review paper is to assess the major challenges and opportunities of milk production in urban dairy farms in Ethiopia. Urban dairy farming is emerging as an important component of the milk production system based on cross breed dairy stock and purchased conserved feeds. Urban milk farming system is concentrated in and around major cities, and towns characterized by a high demand for milk and milk products. The challenges for dairying vary from one location to another or from one production system to another production system. These challenges can be technical like genotype related constraints and reproductive wastage, shortage of animal feed and water resources, shortage of land, animal health problems and non-technical constraints like institutional challenges such as inadequate extension and training services, limited availability of credit to the dairy farmer, absence of operational breeding strategy and policy, waste disposal, limited access and high cost of dairy heifers/cows. The opportunities of milk production in urban dairy farms in Ethiopia such as livestock genetic resources and production system, accesses to services, indigenous knowledge, demand for consumption of milk and milk products and income generation and employment opportunity. Dairying is constitutes an important part of the Ethiopian urban dairy sector, a careful planning of dairy policy, technical and institutional intervention and establishment of dairy processing industries are required for the generation of appropriate and demand driven technologies in order to attain sustainable dairy farm development.
\end{abstract}

Keywords: agro-ecology, cattle, challenges, feed, genotype, milk production, opportunities, Urban

DOI: $10.7176 / \mathrm{JBAH} / 10-21-01$

Publication date: November $30^{\text {th }} 2020$

\section{Introduction}

Ethiopia is one of the developing countries in Africa known with a huge livestock population. The estimated total cattle population for the country is about 60.39 million constituting of male $(45.32 \%)$ and female $(54.68 \%)$. Out of the total cattle population in the country, the proportions of indigenous breeds are $98.24 \%$ and the remaining hybrid and exotic breeds are about $1.54 \%$ and $0.22 \%$, respectively. Dairy-cows are estimated to be around 6.66 million and milking-cows are about 12.39 million heads during the reference period (CSA 2017/2018). But, dairy industry is not developed as that of other east African countries for example Kenya, Tanzania and Uganda (Hunduma 2013).

From other livestock farming in Ethiopia dairy production is an important sector. The huge and diverse cattle populations, diverse and favorable agro-ecology for dairying, long-standing culture of dairy products consumption, increasing demand for dairy products in both peri-urban and urban areas, potential of dairying in the country and favorable policy are indicators. However, the production and productivity of dairy animals in general is insufficient and in short supplies of dairy products and requires the country to spend hard currency to import milk and milk products from out of the country (Azage et al 2013). Dairy production is one of biologically efficient system that converts large amounts of roughage to milk, milk is the most nutritious food known to man. It is also more labor intensive and supports substantial employment in production, processing and marketing (De Leeuw et al 1999).

Almost all over the world including Ethiopia dairying is one of the livestock productions practiced involving a vast number of small, medium, or large-sized, subsistence or market-oriented farms. The difference between large and smallholder farms is mainly determined by herd size (Chagunda et al 2006). Large scale farms were keep large herds of cross breed and include high inputs in terms of land, housing, health management, feed, and labor. Hence, from dairy development point of view, a careful planning is required for the generation of appropriate and demand driven technologies in order to achieve sustainable dairy development.

Like most developing countries, Ethiopia were increase human population, increase urbanization and rising of household incomes are leading to a substantial increase in the demand for livestock products, particularly milk 
and meat. In order to meet the growing demand for milk and milk product in Ethiopia, milk production has to grow at least at a rate of $4 \%$ per annum (Azage et al 2001).

Urban and periurban dairy farming are emerging as an important component of the milk production system. It is based on cross breed dairy stock, mainly Friesian x Zebu and purchased conserved feeds (Staal and Shapiro 1996) and it is contributing immensely towards filling in the large demand-supply gap for milk and milk production in urban center, where consumption of milk and milk product is remarkably high. The sector contributes immensely to the generation and accumulation of asset and poverty alleviation. Almost all of the fluid milk supplied to major urban and peri-urban centers in Ethiopia, for example, comes from urban and peri-urban smallholder and commercial dairy producers; land is the major challenges (Azage and Alemu 1997).

The major challenges for dairy farm development include inadequate veterinary service provision, limited genetic resources, poor management, inadequate animal feed resources, reproductive challenges and market related challenges (Belachew and Jemberu 2002). The poor animal genetic potential for productive traits, low level of animal health care, substandard feeding and management practices are the main contributors to the low productivity (Zegeye 2003). The most common justification to the poor performance of the Ethiopian dairy sector is related to the fasting practices of national consumers (Ahmed et al 2003). Approximately 40\% of the Ethiopian populations are Orthodox Christians (Ahmed et al 2003). The calendar of the Orthodox church involves prolonged fasting periods per year, preceding major Christian festivities, and two fasting days every week (Wednesday and Friday), for a total of 180-250 days of fasting per year. During fasting days/times Orthodox Christians abstain from consuming different animal products including milk and dairy products.

Dairy farm also creates different opportunities which includes; livestock genetic resources and production system, access services and land inputs, agricultural extension services and technologies, income generation and employment opportunities (Goshu 1995). Ethiopian dairy market remains extremely thin and volatile the commercialization of processed dairy products through supermarkets is expanding and is expected to keep doing so in the foreseeable future. Increasing urbanization and corresponding changes in consumer preferences, behaviour and purchasing power are the identified causes for the rise of supermarket-processor dairy chains (Gian Nicola et al 2010). Despite the importance of dairying to the livelihood of farmers, there is little information on Challenges and opportunities of milk production in urban dairy farms in Ethiopia.

\section{Milk production system in Ethiopia}

In the highland areas, agricultural production system is predominantly smallholder mixed farming, with crop and livestock husbandry typically practiced within same management unit. Among the systems milk production is one of biologically efficient system that converts large amounts of roughage to milk, milk is the most nutritious food known to man (Belete 2006).

In Ethiopia, dairying is practiced all over the country by a large number of small or medium or large-sized, subsistence or market-oriented farms. Cattle, camel and goats are the main livestock species that supply milk in Ethiopia, from them cows contributing $81.2 \%$ of the total milk output (Getachew 2003). In Ethiopia, urban and pre-urban areas are used about 300,000 exotic cows for milk production under improved management conditions (Azage et al 2000). Urban and peri-urban milk farming system is concentrated in and around major cities, and towns characterized by a high demand for milk. This system has been developed in response to the fast growing demand for milk and milk products around urban centers (Asaminew 2007).

According to Tsehay (2001) based on their location, milk production systems can be classified into three: urban, pre-urban and rural milk production systems. In general, urban dairy production system are placed in cities and towns, with small or no access to grazing land and small feeding conditions which focus on the production and sale of fluid milk, using the available human and capital resources. Urban dairy production system have a better access to inputs (e.g. feeds) and services (e.g. artificial insemination) provided by the public and private sectors, and use intensive management compared to other systems (Azage et al 2013). Highly specialized, or businessmen owned farms, which are highly involved in urban dairy farming system of the country (Getachew and Gashaw 2001 and Azage 2003).

Due to urbanization around big cities like Addis Ababa, the population density is high and agricultural land is decrease. Pre-urban milk production is developed in these types of areas. Smallholder and commercial dairy farmers sectors in the proximity of Addis Ababa and other regional towns are included and owns the pre-urban milk system (Tsehay 2001). Pre-urban milk production have an access to grazing land, which produces part of the remaining feed in the form of crop (Azage et al 2013). At this time, in the urban and pre-urban areas of the capital, a number of smallholder and commercial dairy farms are emerging (Getachew and Gashaw 2001 and Azage 2003). The primary objective of pre-urban milk production is to generate income from milk sale and main source of feed is both home produced or purchased hay.

According to Azage et al (2013) report generally, both pre-urban production and rural dairy systems have an access to grazing land and practice mixed crop-livestock farming, which produces part of the remaining feed in the form of crop. In urban and peri-urban milk production system, the main feed resources are agro-industrial by- 
products. The total milk production from this system accounts to 34.649 million liters /annum. Of this total, $73 \%$ is sold, $10 \%$ is left for household consumption, $9.4 \%$ goes to calves and $7.6 \%$ is processed mainly into butter and ayib (Azage and Alemu 1998). However, unlike urban dairy production, rural dairy system does not have an access to inputs and services. Household they are handling the process of milk into butter and cottage cheese and sale of butter as well.

According to Ahmed et al (2003) other types of dairy production system are the rural dairy system, which includes pastoralist, agro pastoralist and mixed crop-livestock producers, mainly in the highland areas. The milk produced in rural dairy system is consumed for personal purpose and not market-oriented. The demand for milk by the family and its neighbors, the potential to produce milk in terms of group, and access to a close market is determinant for the level of extra milk (Getachew 2003). Using traditional technologies, the extra milk is processed in to by-product such as butter, ghee; ayib and sour milk which are usually marketed after the households satisfy their needs through the informal market (Tsehay 2001). Rural highland dairy system of Fogera and Bure, which has limited access to urban centers where fluid milk is demanded are focus in these systems on processing of milk into butter and other dairy products for sale and home consumption (Azage et al 2013).

As cited in Adane(2009) milk is one of the most important livestock products and main diet for pastoralists in the Borena pastoral communities. The population and distribution, and the availability of natural grazing land and water are influential for milk production from milking animals (Cattle, camels, sheep and goats). In addition, there are also other important factors which influencing milk production in the pastoral systems such factors as types of animal breeds, the composition of milking animals in herd etc. The milk production also influenced by the environmental situation. The milk production will better if the environment is comfortable and vice versa.

Intensive dairy farming is a more specialized dairy farming system practiced in state sector and very few individuals on commercial basis. The urban, peri-urban and intensive dairy farmers produce $2 \%$ of the total milk production of including in severe technical, institutional and policy challenges in the country. The commercial farmer herd is dominated with improved (cross breed dairy cattle) and the production system is market oriented and milk production is for sale (surplus production) (Ahmed et al 2003). Milk production system is highly concentrated by the most specialized and high-tech system, few industries and governmental sectors are highly practiced in milk production system on commercial basis in and around Addis Ababa (Belete 2006).

\section{Challenges of milk production in urban dairy farms in Ethiopia}

There are multiple factors which constrain dairy production, even the nature and magnitude of the problems different between production systems and agro-ecologies. Some factors are cross-cutting regardless of dairy production system and agro ecologies that can have influence on dairy production; others are system specific (Azage et al 2013).

There are a number of challenges which faced the dairy farm development. These include limited genetic resources, inadequate veterinary service provision, inadequate animal feed resources, poor management, reproductive challenges and market related challenges (Belachew and Jemberu 2002). The poor genetic potential for productive traits, low level of health care, substandard feeding and management practices are the main contributors to the low productivity of this sector (Zegeye 2003).

The most important constraints associated with milk production as ranked according to their importance by the farmers were feed shortage, shortage of water, access to land, disease prevalence, poor genetic potential of local cows for milk production, inadequate artificial insemination services, and shortage of farm labor. The total production of milk in the area was affected by the interaction of these constraints (Asaminew and Eyassu 2009). Shortage of feed, dairy cow disease, absence of improved dairy production technologies and shortage of capital were the major constraining factors of dairy production in Jima Town (Zekarias and Shiferaw 2012).

Belay et al (2011) reported that the major constraints to dairy production were lack of land (50\%), shortage of feed (38.9\%), lack of improved animas (5.6\%) and lack of access to artificial insemination (3.7\%) and these constraints limit dairy production in Jimma town. According to Solomon (2014) the major challenges of dairy production in Mekelle City were shortage of feed, high costs of feeds, seasonality of milk demand occurred due to fasting season, access to credit, inadequate land for dairy expansion and preparation of feeds, Artificial insemination problem, shortage of water. This area was dominated by both urban and pre-urban milk production.

The structure and performance of livestock and its products marketing both for domestic consumption and for export is generally perceived poor in Ethiopia. These challenges faced dairy industry in various level including technical challenges, institutional, policy and socio-economic challenges reduce the reproductive and production potential of dairy production farming (Belachew and Jemberu 2003).

\section{Technical Challenges}

\section{Genotype related constraints and reproductive wastage}

Out of 59.5 million, total cattle population in Ethiopia, the proportion of indigenous breeds are $98.2 \%$ and the remaining hybrid and exotic breeds are about $1.62 \%$ and $0.18 \%$, respectively (CSA 2016/2017). In contrast, Kenya, 
with cattle population of about 12 million, the proportion of cross breed dairy cows has around three million (Azage et al 2016). According to Azage et al (2013) the number of crossbred cows found in Ethiopia was very low and is mainly concentrated in and around major urban and peri-urban centers. The greater parts of the farmers saying that exotic animals are influenced by environmental factors such as feed shortage and diseases as compared to local cows. To get better milk production through exotic animals in the district level would be very hard (Kedija 2007).

Reproductive efficiency is a critical component of successful dairy operation and act as an important component for the profitable of dairy farm, whereas reproductive inefficiency is one of the most costly problems facing the dairy industry today. Low fertility reduces the profit by decreasing the average milk production and the number of calves per cow per year. In dairy production the reproductive performance were influenced by the interactive effect of genetic, environment, management, and animal health factors (Gröhn and Rajala-Schultz 2000).

The largest part of milk and milk products are obtained dominantly by the native cattle breeds in Ethiopia (Azage et al 2013; Belete 2006; Ketema and Tsehay 2004 and Sintayehu et al 2008). As compared to the huge livestock potential, the contribution to the production has shown low productivity although the country owns the largest livestock population. The result was due to their low inherited capacity for particular animal products and lack of knowledge about the native breeds (Getachew and Gashaw 2001).

There is shortage of crossbred dairy animals in urban and peri-urban areas where the demand for milk and milk products is high. There is no breeding policy in place in the country to curb genotype related problems and thereby make genetic resource utilization sustainable. Delayed age at first calving, long calving interval and low calving rate in improved dairy genotypes have important problems in the urban and peri-urban dairy production systems (Azage et al 2013. If improvement of the local Ethiopian breeds for milk production is targeted, then it is important to have a designed selection program in place for a few selected promising breeds (Tesfaye 1990).

Improving the feeding management, water availability and animal health care of indigenous cattle did not increase significantly the quantity of milk per day to allow the animals to be used for commercial market-oriented milk production (Belachew and Jemberu 2003). In order to improve the low productivity of dairy cattle, selection of the most promising breeds and cross breeding of these indigenous/local breeds with highly productive exotic cattle have been considered a practical solution (Tadesse 2010).

\section{Shortage of Animal Feed and water Resources}

Feed shortage in terms of quality and quantity and access to water during the dry season in the dairy production system was the major constraint. According to Azage et al (2013) the general belief that feed is abundant during the wet season is not true in all production systems and agro-ecologies. The most important limitations associated with milk production were feed and water shortage in Bahir Dar Zuria and Mecha Woreda (Asaminew and Eyassu 2009).

The major feed resources identified in Mekelle city included, hay and roughage, pasture and non-usual feed like "Attela" (local brewery by product). The major feed sources of the dairy producer were purchasing the feed from the crop farmers. However, there was feed shortage mainly during March to October due to many reasons such as lack of raw materials or ingredients for preparation of roughage, lack of enough rainfall, and high cost of feed (Solomon 2014).

Feed shortage is one of the limiting factors for increasing production and productivity of dairy cattle in most of the agro-ecological zones in Ethiopia. In line with this the feed requirements of those cross breed dairy animals is very high compared with the local indigenous cattle due to their enormous size and productivity levels (Yilkal and Kassahun 2015). The feed shortage is mostly face during the months between May and June as well as between December and February (Kedija 2007). According to (Asaminew and Eyassu 2009; Belay et al 2011; Azage et al 2013; Solomon 2014) feed shortage is the major problem in urban and pre-urban dairy farming system. To deal with the problem the water harvesting practice is not developed in the areas of urban and pre-urban dairy farming system.

\section{Shortage of Land}

Dairy farms in urban and pre-urban dairy farming system are under remarkable pressure to expand dairy production mainly due to rapid urbanization and human population growth. Most urban dairy producers (97\%) keep their cattle within their own residence compound (Azage et al 2013). According to (Sintayehu et al 2008; Asaminew and Eyassu 2009; Belay et al 2011; Azage et al 2013; Solomon 2014) land scarcity is also another major problem in urban and pre-urban dairy farming system. In rural area farmers have more livestock numbers and large hectare of land compared with those living in the town/urban. The possible reason might be the population is more densely and human population per unit area is high in the town/urban leading to shortages of land and livestock (Yilkal and Kassahun 2015). 


\section{Animal Health Problems}

Diseases in dairy animals affect reproduction, milk production, milk quality and cause for mortality and morbidity of dairy animal and calves (Azage et al 2013). Livestock disease is also another one of the difficult factor for dairy development in the different region. The trouble is more worsened with either by deficiency or unsatisfactory of veterinary services (Adane 2009; Alganesh et al 2013; Asaminew and Eyassu 2009; Azage et al 2013; Belachew and Jemberu 2002; Belete 2006; Getachew and Gashaw 2001 and Ketema and Tsehay 2004). The animal health services provided are insufficient, the drugs costs is very high, while the diagnostic services are not readily accessible to the dairy farmer. This is partially attributed to the insufficient for budget allocated to veterinary services. The overall diseases occurrence was reported $46.8 \%$ in urban and $33.6 \%$ in per-urban in the central highlands (Lemma et al 2008 and Teferra and Abay 1993).

The common dairy cow diseases namely anthrax, foot and mouth disease and liver fluke were found to have a significant impact on milk yield in Jima Town (Zekarias and Shiferaw 2012). According to Asaminew and Eyassu (2009) report the main common diseases in Bahir Dar Zuria and Mecha districts are trypanosomiasis, mastitis, dermatophilosis and anthrax. Poor veterinary service has also been reported in urban and peri-urban system of Shashemene-Dilla milk shed areas (Azage et al 2013).

\section{Institutional Challenges}

\section{Inadequate Extension and Training Services}

Adequate and effective extension services, advice on animal feeding management, training in milk handling, processing and marketing, hygiene, reproduction, extension works to transfer new technologies, farm management and dairy production efficiency are not always available to urban dairy farmers. There is no adequate and effective extension service to supply information about dairy technologies to improve the production, handling and marketing to estimate certain dairy development. A shift towards a developed dairy production requires more support from consultative services and more active links with research services (Tesfaye 1990). In the urban and peri-urban dairy system of Shashemene-Dilla milk shed, some dairy producers receive dairy production extension services, but it was not supported with practical demonstration. In fact most dairy producers started dairy farming without prior knowledge and skill in dairying as reported in the urban and peri-urban system (Azage et al 2013).

The flows of information systems from agricultural researches such as new technologies, extension service and policy to dairy farmers are not organized (weak). This weakness system partially from the absence of sound linkage polices in the agricultural knowledge generation and transfer systems (Goshu 1995). There are shortages of qualified personnel, miss understanding of production systems, poor education and management expertise of farmers, ignorance of the experience and knowledge of local farmers, lack of knowledge gained through researches to farmers, absence of forums for consultation and discussion with the farmers (EARO 2000). According to Zekarias and Shiferaw (2012) the activity of the research center and some NGOs in the Jima town are largely related with the production of crops such as coffee and cereals. Therefore technology generation and dissemination activities in the area of livestock sector in general and dairy sub-sector in particular has been given less attention in the last few years.

\section{Limited Availability of Credit to the Dairy Farmer}

In the livestock development master plan especially in dairy sector establishing credit facilities is crucial step to the country (Azage et al 2000). The credit services existing to dairy production is by far minimal compared to crop production. In urban and peri-urban dairy production system of Shashemene-Dilla milk shed areas, only $12.5 \%$ of the dairy producers have access to credit service. On the other hand, about $25 \%$ of butter and milk traders in this milk shed have shortage of working money and need credit service to expand and improve their business. In fact there is also lack of awareness about the importance of credit between dairy producers as demonstrated in the rural dairy system of Bure and the urban and peri-urban dairy system of Shashemene-Dilla milk shed. In general, the credit service (system) for dairy development is not well advanced (Azage et al 2013).

\section{Absence of Operational Breeding Strategy and Policy}

The absence of effective breeding program is the major challenges to the dairy development. The AI services have been inefficient for different reasons. Some of these reasons include: inefficient heat detection, improper timing of insemination, managerial and financial challenges, inappropriate infrastructure, embryonic death and very small numbers of AI technician (Shiferaw et al 2003 and Tesfaye 1990). Although the country has favorable macro policy for agricultural development sector in general, there is lack of specific workable policy direction and support for dairy development (Azage et al 2013).

AI service is available in most urban areas of Shashemene-Dilla milk shed area. Currently, AI service has been expanding to different parts of the country. However, the efficiency and effectiveness of AI service in general is quite low due to various constraints. For example, dairy producers in Fogera and Bure reported that pregnancy rate to $\mathrm{AI}$ is low and they prefer to breed their animals naturally using crossbred bulls. There is no record keeping 
tradition at AI centers and thus information on pregnancy rate, number of calves born to AI etc. is not available (Belete et al 2010). Farmers in Bure are reluctant to use AI and they reported that AI yields in high incidence of male animals than females (Adebabay 2009).

\section{Waste Disposal}

Waste from dairy farms is a serious problem, particularly in urban production system. If not properly managed, manure is a source of bad odor and flies, source of conflict with neighbors, and source of zoonotic diseases. Dairy producers from urban dairy system complained that manure disposal incurs cost. Although urban dairy farming is recognized by public authorities in some urban centers, it was not encouraged in others and so there is lots of pressure and restrictions on dairy producers (Azage et al 2013).

\section{Limited Access and High Cost of Dairy Heifers/cows}

The improved cross breed, grade and pure exotic dairy cattle are usually in short supply and when available the high cost is a major problem. The previous government cross breed heifers multiplication centers that used to distribute cross breed heifers to producers at reasonable prices have been sold after the introduction of the privatization policy. Prices of cross breed cows and heifers are now unaffordable by the poor smallholder farmers that would have liked to engage in the dairy business (Shiferaw et al 2003). The productivity of cross and pure breeds is by far better than those of the local breeds. However the number of these improved breeds is few and most of the breeds are on the hands of urban dairy sector (Zekarias and Shiferaw 2012).

\section{Opportunities of milk production in urban dairy farms in Ethiopia}

In Ethiopia, there are number of opportunities for dairy development. The large and diverse dairy animals genetic resources, diverse agro-ecologies, establishment of several structures and service centers such as veterinary health and artificial insemination (AI) centers, extensive service of agricultural extension, high demand for consumption of dairy products, high rate of urbanization, increase income growth, huge human population with long-standing tradition of consumption of dairy products, availability of trained manpower, research institutions and technologies shows that the country has good opportunity for dairy development (Azage et al 2013).

\section{Livestock Genetic Resources and Production System}

Ethiopia is endowed with huge and diverse dairy animal genetic resources, which are widely distributed across the various agro-ecologies and climatic conditions widespread in the country. The country with about 27 breeds of cattle is considered as a center of diversity for farm animal genetic resource. Indigenous animals have evolved over time through natural selection and adaptation to the existing diverse agro-ecologies conditions of their habitat (DAGRIS 2007). Livestock production is dominant to sustain the livelihood of society to market oriented urban and per-urban dairy production system that exists in mid to upper highlands (ILCA 1993).

The milk yield among the indigenous animals is variable improving that there are an opportunities for dairy cattle improvement (Belete 2006). High demand of milk and milk products, favorable agro ecology to animal and high milk yield from cross breed dairy cows were assessed as the golden opportunities of dairy production (Yilkal and Kassahun 2015).

\section{Accesses to Services}

Dairy development depends on reliable services such as health service and Artificial Insemination service (Muriukia and Thorpe 2001). Currently, the numbers of AI service centers has been established, increased and cover most urban and per-urban areas (Ibrahim and Olaloku 2000). This is an opportunity to improve the genetic potential of indigenous dairy animals in the urban area where there is critical shortage of dairy products (Solomon 1991). Cognizant of the fact that diseases and parasitic infestations are economically important to reduce dairy production, several public veterinary clinics have been established across the different dairy production systems in the country, although its efficiency of operation is low (Kedija 2008).

\section{Indigenous Knowledge}

The diverse and favorable agro-ecologies and existence of diverse dairy production system combined with diverse flora of species rendered the country to have indigenous knowledge, especially in the areas of livestock production and dairy processing. For instance, strong indigenous knowledge exists in the preservation of milk and milk product in the agro-pastoral dairy system in the rural and urban highland dairy system using various sources of herbs (Belete 2006).

\section{Demand for Consumption of Milk and milk products}

Although, the contribution of cow milk is dominant, milk from camels and goats are also consumed in Ethiopia, especially in pastoral and agro-pastoral systems of production. In Ethiopia there is long standing and strong culture 
of consumption of milk and milk product products. In addition to raw milk, milk products, such as cottage cheese, butter, whey and fermented milk (yogurt) are also commonly consumed (Azage et al 2013). The large human population (estimated at more than 110 million and expected to grow at $2.7 \%$ per annum) and very high rate of urbanization, improved income in some segments of the society, are also among the major driving forces that dramatically increase the demand for milk and milk products.

\section{Income generation and employment opportunity}

Dairy farming supports livelihoods of society under low input production system; generates income and creates employment opportunity under market-oriented production system. Dairy farmers in urban, peri-urban and rural dairy production systems demonstrated strong interest to expand dairying as one of the means of income generating activity. Particular attention should be paid to increase the role of women in dairy development, since some studies shows that they play a major role in dairy production and marketing (Azage et al 2013).

\section{CONCLUSION}

- Dairy farming constitutes an important part of the Ethiopian urban dairy sector, which plays a crucial role for economic development of the country as a source of food and income and making it one of the biggest potential producers of milk and milk products.

- In order to improve urban dairy production there is a need for technical and institutional intervention which is needed to alleviate the identified problems through dissemination of appropriate technologies for better feeding, artificial insemination service, improved dairy animals supply and access to land, which will significantly increase milk production and animal performance.

- As dairying constitutes an important part of the Ethiopian urban dairy sector, a careful planning of dairy policy is required for the generation of appropriate and demand driven technologies in order to attain sustainable dairy farm development.

- Supporting dairy producers and cooperatives for the establishment of dairy processing industries and improving access to services like credit, land, water, feed, etc. should receive due attention in order to improve dairy production in urban dairy production.

\section{References}

Adane 2009 Value Chain Analysis of milk and milk Products in Borana Pastoralist Area, Addis Ababa, Ethiopia. Adebabay Kebede 2009 Characterization of milk production systems, marketing and on-farm evaluation of the effect of feed supplementation on milk yield and milk composition of cows at Bure district, Ethiopia. MSc Thesis. Bahir Dar University, Ethiopia.

Ahmed, M.A.M., Ehui, S., Yemesrach, A. 2003 Dairy Development in Ethiopia.ILRI working paper no. 58. Addis Ababa, Ethiopia.

Asaminew Tassew and Eyassu Seifu 2009 Smallholder Dairy Production System and Emergence of Dairy Cooperatives in Bahir Dar Zuria and Mecha Woreda, Northwestern Ethiopia. World Journal of Dairy \& Food Sciences 4 (2): 185-192, 2009. Andassa Livestock Research Center, Bahir Dar, Ethiopia.

Asaminew Tassew 2007 Production, handling, traditional processing practices and quality of milk in Bahir Dar milk shed Area, Ethiopia. M.Sc. Thesis. Alemaya University, Ethiopia.

Azage Tegegne, Tsehay Reda, Alemu Gebrewold and Hizkias Ketema 2000 Milk recording and herding registration in Ethiopia: an essential step towards genetic improvement for milk production. In proceedings of the 8th National Conference of the Ethiopian Society of Animal Production (ESAP). 24-26 August 2000. Addis Ababa, Ethiopia. pp 90-104.

Azage Tegegne and Alemu G/Wold 1998 Prospects for peri-urban milk development in Ethiopia. In: Proceedings of $5^{\text {th }}$ National Conference of Ethiopian Society of Animal Production (ESAP), 15-17 1997, Addis Ababa. Ethiopia, pp 248.

Azage Tegegne 2003Financing market oriented dairy development: the case of Ada'aLiben district Dairy Association, Ethiopia. Urban Agricultural Magazine.No. 9. Koninklijke, Netherlands.

Azage Tegegne, Berhanu Gebremedhin, Dirk Hoekstra, Berhanu Belay and Yoseph Mekasha 2013 Smallholder dairy production and marketing systems in Ethiopia: IPMS experiences and opportunities for market-oriented development. Pp 65.

Azage, T. and G. Alemu 1997 Prospects for peri-urban dairy development in Ethiopia. In: proceedings of the 5 National Conference of the Ethiopia Society of Animal Production (ESAP), 15-17 May 1997, Addis Ababa, Ethiopia, pp: 28-39.

Azage, T., R. Tsehay, G. Alemu and K. Hizkias 2001 Milk recording and herd registration in Ethiopia. In Proceedings of the 8 Annual Conference of the Ethiopian Society of Animal Production (ESAP), 2426August 2000, Addis Ababa, Ethiopia, pp: 90-104.

Azage, T., T. Million, Y. Alemu and M. Uaset 2000 Market-oriented urban and peri-urban dairy systems. Urban 
Agricultural magazine (The Netherlands), pp: 23-24.

Belachew Hurrissa and Jemberu Eshetu 2002 Challenges and opportunities of livestock marketing in Ethiopia, Proceedings of the $10^{\text {th }}$ annual conference of the Ethiopian Society of Animal Production (ESAP). Addis Ababa, Ethiopia, 22-24 August 2002, Addis Ababa, Ethiopia. Pp: 1-13.

Belachew, H. and E. Jemberu 2003 Challenges and opportunities of livestock marketing in Ethiopia. In: proceedings of the 10 annual conference of the Ethiopia Society of Animal Production (ESAP), held in Addis Ababa, Ethiopia, 21-23 August 2003, ESAP, Addis Ababa, Ethiopia, pp: 1-13.

Belay Duguma, Yisehak Kechero and G.P.J. Janssens 2011 Analysis of Constraints Facing Urban Dairy Farmers and Gender Responsibility in Animal Management in Jimma Town. Libyan Agriculture Research Center Journal International 2 (4): 155-160, 2011 ISSN 2219-4304.

Belete Anteneh 2006 Studies on cattle milk and meat production in Fogera district: Production systems, constraints and opportunities for development. M.Sc. Thesis. University of Hawassa, Hawassa, Ethiopia.

Belete Anteneh, Azage Tegegne, Fekadu Beyene and Berhanu Gebremedhin 2010Characterization of cattle milk and meat production and marketing system and opportunities for market-orientation in Fogera Woreda, Amhara Region, Ethiopia. IPMS Working Paper No. 19. Nairobi: ILRI.

Chagunda, M.G.G., A.C.M. Msisko, C.B.A. Wollny, H. Tchale and J.W. Banda 2006 An analysis of smallholder farmers' willingness to adopt dairy performance recording in Melawi. Livestock Research for Rural Development, 18: 66 Retrieved 6 June, 2013.

CSA (Central Statistical Agency) Federal Democratic Republic of Ethiopia 2017/2018 Agricultural Sample Survey Report on livestock and livestock characteristics (private peasant holdings). Addis Ababa, Ethiopia.

DAGRIS (Domestic Animal Genetic Resources Information System) 2007 International Livestock Research Institute, Addis Ababa, Ethiopia. (Available from http://dagris.ilri.cgiar. org).

De Leeuw, P.N; A.Omore, S. Staal, and W. Thorpe 1999 Dairy production systems in the tropics. ILRI (International Livestock Research Institute), Nairobi, Kenya.

EARO (Ethiopian Agricultural Research Organization) 2000 Summary of Livestock Research Strategy.EARO, Addis Ababa, Ethiopia.

Getachew Felleke and Gashaw Geda 2001The Ethiopian Dairy Development Policy: A Draft Policy Document. Ministry of Agriculture, Addis Ababa, Ethiopia.

Getachew Felleke 2003 Milk and Dairy Products, Post-harvest Losses and Food Safety in Sub Saharan Africa and the Near East.A Review of the small scale milk sector in Ethiopia.

Gian Nicola Francesconi, Nico Heerinkb and MarijkeD'Haesec 2010 Evolution and challenges of dairy supply chains: Evidence from supermarkets, industries and consumers in Ethiopia. Journal homepage.

Goshu, M. 1995 Agricultural research and extension in Ethiopia. In: proceedings of the $4^{\text {th }}$ Annual Conferences on the Ethiopian Economy, 1995. Addis Ababa, Ethiopia, pp: 373-390.

Gröhn, Y.T. and P.J. Rajala-Schultz2000 Epidemiology of Highlands of Ethiopia. Tropical Animal Health Production, 25: 551-561.

Hunduma Dinka 2013 Reproductive performance of crossbred dairy cows under smallholder condition in Ethiopia. African Journal of Dairy Farming and Milk Production (AJDFMP) 1: 101-103.

Ibrahim, H. and E. Olaloku 2000 ILRItraining manual and imploring cattle for milk, meat and traction. International livestock research institute (ILRI), pp: 6-23.

ILCA 1993 Hand book of African livestock statistics.ILCA, Addis Ababa, Ethiopia. pp: 66.

Kedija Husien 2007 Characterization of milk production system and opportunity for market orientation: A Case Study of Mieso District, Oromia Region, Ethiopia. M.Sc. Thesis. Haramaya University, Ethiopia.

Kedija, H.H. 2008 Characterization of milk production system and opportunity for market orientation: A case study of Mieso district, Oromia region, Ethiopia. MSc thesis, Haramaya University, Ethiopia.

Ketema, H. and Tsehay, R. 2004 Milk production systems in Ethiopia.Ministry of Agriculture, Addis Ababa, Ethiopia.

Lemma, T.A. Tegegne, R.R. Puskur, P. Ranjitha and D. Hoekstra 2008 Moving Ethiopian smallholder dairy along a sustainable commercialization path: Missing links in the innovation systems: Improving Productivity and Market Success (IPMS) Project, ILRI, Addis Ababa, Ethiopia.

Muriukia, H.G. and W. Thorpe 2001 Regional synthesis: Smallholder Dairy Production and Marketing in East and South Africa. In: Proceeding of the South-South Workshop on Smallholder Dairy Production and Marketing-Constraints and Opportunities. March 12 -16, 2001, NDDB (National Dairy Development Board) and ILRI (International Livestock Research Institute).

Shiferaw, Y., B.A. Tenhagen, M. Bekana and T. Kasa 2003 Reproductive performance of cross breed dairy cows in different production systems in the central high lands of Ethiopia. Tropical Animal Health Production, 25: 551-561.

Sintayehu Yigrem, Fekadu Beyene, Azage Tegegne and Berhanu Gebremedhin 2008 Dairy production, processing and marketing systems of Shashemene-Dilla area, South Ethiopia. IPMS (Improving Productivity 
and Market Success) of Ethiopian Farmers Project Working Paper 9.ILRI, Nairobi, Kenya.

Solomon Mebrahtu 2014 Exploration of Challenges and Prospects of Dairy Production: A survey study of Mekelle City, Ethiopia. MSc. Thesis Mekelle University, Mekelle, Ethiopia.Pp 80.

Solomon-Bekure, DeLeeuco, P.N., B.E. Grahdin and P.J.H. Nate 1991Maasai pastoralists in eastern Kajiado district, Kenya. ILCA systems.Study 4. Addis Ababa, Ethiopia: ILCA (International Livestock Center for Africa).

Staal, S. and B. Shapiro 1996The economic impact of public policy on smallholder peri-urban producers in and around Addis Ababa, ESAP (Ethiopia Society of Animal Production) publication 2. ESAP, Addis Ababa, Ethiopia.

Tadesse, A. S. 2010 The Status and Constraints of Artificial Insemination in Cattle in the Three Selected Districts of Western Gojjam Zone of Amhara Region, Ethiopia. MSc. Thesis, Bahir Dar University, Bahir Dar, Ethiopia.

Teferra, G. and T. Abay 1993 Development opportunities in Animal Agriculture. In: Proceedings of the 2 National Conference of ESAP, 26-27 May 1993, Addis Ababa, Ethiopia, pp: 91-110.

Tesfaye, A. 1990 Livestock development in the peasant sector of high lands of Ethiopia: some policy issues and implications. In: Africa livestock policy analysis network (SLPAN), Network paper No. 24, June 1990, ILCA, and Addis Ababa, Ethiopia.

Tsehay Redda 2001 Small-scale milk marketing and processing in Ethiopia.Ministry of Agriculture, Addis Ababa, Ethiopia.

Yilkal Tadele and Kassahun Ahmed 2015 Assessment on Challenges and Opportunities of Introducing Exotic Dairy Cattle Breeds at Smallholder Level in Chencha District, Southern Ethiopia. Volume 2 (1), pp: 49-62.

Zegeye Yigezu 2003 Challenges and opportunities of livestock marketing in Ethiopia. In: Proceedings of the 10 annual conference of Ethiopian Society of Animal Production (ESAP), 22-24 August 2002 held in Addis Ababa, Ethiopia, pp: 47-54.

Zekarias Shumeta and Shiferaw Mulugeta 2012 Milk Supply Shortfall in Jima Town-An Option for Investment. World Journal of Agricultural Sciences 8 (4) Pp: 366-374. 